\title{
LIMITES E RUPTURAS NA ESFERA DA INFORMAÇÃ̃O
}

Laymert Garcia dos Santos

Professor do Instituto de Filosofia e Ciências Humanas da Unicamp

\begin{abstract}
Resumo: Controlar os consumidores e principalmente monitorar as potencialidades de cada uma das dimensões de suas vidas tornam-se uma exigência do próprio processo do capitalismo contemporâneo, impondo a coleta e o tratamento de informações. Ora, se lembrarmos que uma parcela cada vez maior da vida e das atividades do homem contemporâneo tende a passar pelas redes, quem melhor colocado para acessar os seus dados senão os provedores de acesso ao ciberespaço?

Palavras-chave: controle digital; informação e consumo.
\end{abstract}

$\mathrm{N}$ o dia $1^{\circ}$ de julho último, o jornal Los Angeles Daily News publicou um artigo de David Bloom intitulado: "Internet oferece voyeurismo em tempo integral". Nele o jornalista relata como a vida privada pode hoje não ser simplesmente vivida, mas exposta e encenada para um público de telespectadores que não se contenta mais com os programas de realidade na televisão, nem com o sexo ao vivo dos sites de pornografia, mas quer agora poder assistir a vida em tempo real (Bloom, 2000). ${ }^{1}$

Aprendemos, então, que há vários sites de Lifecam, com nomes sugestivos: AspiringActresses.com, Crushedplanet.com, TheRealHouse.com, CoupleTV, FirstApartment.com. Neles, jovens que querem sair do anonimato, exibicionistas, gente em busca de uma experiência diferente, estudantes, aceitam viver suas vidas para as câmeras da web e interagir com os fãs, em troca de parte da renda paga por assinantes mensalistas, dividida com os proprietários dos sites. Dá para pagar algumas contas e não precisar "ter de ser garçonete sete noites por semana" - declara Lisa Nowicki, cujo cotidiano é bisbilhotado diariamente por cerca de quatro mil espectadores de todo o mundo que, segundo o proprietário do site, mantêm uma janela aberta em seus computadores para monitorar o que está acontecendo na vida dela, enquanto vivem as suas próprias.

À experiência de Lisa e de tantos outros exibicionistas da rede, valeria a pena acrescentar a de June Houston, relatada pelo jornal Le Monde (em 18 de novembro de 1997) e analisada por Paul Virilio em La bombe informatique. Como conta o pensador das tecnologias, essa americana de 25 anos instalou 14 câmeras em pontos estratégicos de sua casa para lutar contra os fantasmas que parecem assombrá-la. Tais câmeras estão ligadas e conectadas à rede para captar e transmitir aos visitantes do site Fly Vision as aparições que porventura vierem a se manifestar. Graças a uma janela interativa, os "espreitadores de fantasmas" podem alertar por $e$-mail a presença de algum "ectoplasma". "É como se os internautas se tornassem meus vizinhos, testemunhas do que acontece comigo", diz June Houston, acrescentando: "Não quero que as pessoas venham fisicamente ao meu espaço. Não podia portanto receber ajuda externa, até que compreendi o potencial da Internet" (Virilio, 1998:70).

É evidente que, aqui, não se trata de transformar o lar num palco para a encenação da vida privada; mas sim, como bem percebeu Paul Virilio, de torná-lo objeto de uma televigilância diferente daquela a que estamos habituados. Com efeito, diz o pensador da tecnologia, não se trata mais de se precaver contra a intrusão de ladrões, mas de compartilhar as angústias e os medos com toda uma rede, graças à superexposição do local onde se vive. $\mathrm{Na}$ verdade, segundo Virilio, estamos diante da emergência de um novo tipo de TELE-VISÃO, cujo objetivo não é mais informar ou divertir a massa de telespectadores, mas expor e invadir o espaço doméstico com uma nova ilumi- 
nação capaz de revolucionar a noção de vizinhança. "Graças a esta iluminação em "tempo real", escreve Virilio, o espaço-tempo do apartamento de cada um torna-se potencialmente comunicante com todos os outros, e o medo de expor sua intimidade cotidiana dá lugar ao desejo de superexpô-la aos olhares de todos, fazendo que a tão temida vinda dos "fantasmas" seja para June Houston apenas um pretexto para a invasão de seu domicílio pela "comunidade virtual" dos inspetores, dos investigadores furtivos da Internet" (Virilio, 1998:70).

Virilio vê nessa espécie de luz indireta, que devassa todos os cantos da vida cotidiana de June Houston e de todos os exibicionistas da Internet, a expressão de um processo mais amplo, generalizado, de superexposição de todo tipo de atividade, no mercado global. Como se tudo precisasse ser mostrado e propagandeado incessantemente, como se tudo pudesse ser observado e comparado a todo momento. "Hoje, comenta Virilio, o controle do ambiente suplanta (...) em larga medida o controle social do Estado de direito e, para tanto, deve instaurar um novo tipo de transparência: a transparência das aparências instantaneamente transmitidas à distância..." (Virilio, 1998:72).

A nova televigilância e esse novo tipo de transparência, porém, não são exercidas unicamente por meio da transmissão de imagens digitalizadas das pessoas e de seu ambiente doméstico, controlados à distância. Há um modo muito mais sutil e perverso da vigilância eletrônica violar a privacidade, método que prescinde da instalação de câmeras no espaço domiciliar e até mesmo do consentimento do vigiado que se encontra superexposto. Trata-se do cruzamento e processamento dos dados que cada um de nós gera ao entrar, sair e transitar nos diversos sistemas informatizados e nas diversas redes que compõem a vida social contemporânea.

Diferentemente dos exemplos mencionados anteriormente, o que será invocado agora para explicitar esse controle à distância foi extraído de Idoru, o último livro de ficção científica de William. A escolha desse exemplo fictício é propositada: o que interessa é perceber por um casolimite a lógica de um processo que se encontra em franca, e aparentemente irrefreável, expansão.

Colin Laney, o personagem central de Idoru, é um internauta que gosta de ver a si mesmo como pesquisador. Mas não é um voyeur. O narrador descreve-o da seguinte maneira: "Tinha uma aptidão peculiar com a arquitetura de compilação de dados e um déficit de atenção documentado medicamente que ele conseguiu transformar, sob certas condições, num estado de hiperfocalização pa- tológica. Isso fazia dele (...) um pesquisador extremamente competente. (...) O dado relevante (...) era o fato de ele ser um pescador intuitivo de padrões de informação: do tipo de assinatura que um indivíduo inadvertidamente cria na rede na medida em que vai dando seguimento ao ofício mundano e, no entanto, infinitamente multiplex, de viver numa sociedade digital. O déficit de atenção de Laney, pequeno demais para ser registrado em algumas escalas, fazia dele um zapeador natural de canais, indo de programa a programa, de um banco de dados a outro, de plataforma a plataforma, de um modo bem... intuitivo" (Gibson, 1999:32).

Laney é, portanto, mais do que um navegador competente; ele conjuga seu conhecimento dos processos informacionais a um déficit de atenção que na verdade é um ganho. Assim como o psicanalista, que ouve seu paciente com a atenção flutuante e por isso mesmo capta intuitivamente na trama da fala a falha de seu discurso e a irrupção do desejo, Laney, zapeando na esfera digital, focaliza no cruzamento dos padrões e na teia dos dados uma peculiaridade informacional, a diferença qualitativa que confere novo relevo ao conjunto e conduz o investigador a túneis de informação "que poderiam ser seguidos até um outro tipo de verdade, outro modo de saber, bem no fundo de minas de informação". Essas singularidades, o internauta chama "pontos nodais".

É importante sublinhar que Laney trabalha para um programa na rede, um certo tipo de noticiário que faz e desfaz celebridades para um público perpetuamente faminto da sua vida íntima; na verdade, uma versão hiper high-tech dessa imprensa sensacionalista que está crescendo e proliferando no Brasil. Ali o internauta integra a equipe que se dedica aos aspectos mais privados das vidas dos ricos e famosos; e no exercício de sua função, uma coisa começa a ficar clara para Laney: a mulher que ele televigia descobre que está sendo controlada. Escreve o narrador: "Alison Shires sabia, de alguma forma, que ele estava lá, observando. Como se ela pudesse senti-lo olhando para o mar de dados que eram um reflexo da sua vida: sua superfície feita de todos os pedaços que formavam o registro diário de sua vida à medida que ficava registrada na tecitura digital do mundo. Laney viu um ponto nodal começando a se formar a partir do reflexo de Alison Shires. Ela ia cometer suicídio" (Gibson, 1999:46).

$\mathrm{O}$ trecho acima merece algumas considerações. Em primeiro lugar, convém notar que Laney não vê diretamente nem a imagem nem a performance de Alison Shires, mas sim o diagrama, isto é, as linhas de força e as tendên- 
cias que se desenham a partir do processamento dos dados que ela vai gerando enquanto vive. Laney faz uma leitura desse diagrama, que torna a vida de Shires transparente para o internauta. Escreve o narrador: "Ele nunca a havia encontrado, ou falado com ela, mas acabara conhecendo-a, ele achava, melhor do que alguém já a conhecera ou conheceria. Maridos não conheciam suas esposas deste jeito, ou esposas a seus maridos. Espreitadores podiam aspirar a conhecer os objetos de suas obsessões desse modo, mas nunca conseguiam" (Gibson, 1999:5354). A vida de Shires tornara-se transparente, mas segundo esse novo tipo de transparência apontado por Virilio: a transparência das aparências instantaneamente transmitidas à distância. Laney olha o mar de dados que refletem a vida de Shires, olha essas aparências que são instantaneamente transmitidas à distância, à medida que vão sendo registradas na tecitura digital do mundo. Laney olha e lê - e é a leitura que faz das aparências transparência, é a leitura que torna cristalina a evolução de uma vida, é a leitura que anuncia por um ponto nodal a inflexão dessa vida rumo à morte.

Para entender melhor o que se quer dizer, talvez convenha reproduzir as palavras do narrador quando descreve como Laney trabalha: "O ponto nodal estava diferente, embora ele não tivesse linguagem adequada para descrever a mudança. Peneirou os incontáveis fragmentos que haviam se aglutinado ao redor de Alison Shires em sua ausência, procurando a fonte de sua convicção anterior. Baixou as músicas que Alison havia acessado enquanto ele estivera no México, tocando cada música na ordem em que ela as havia selecionado. Descobriu que as escolhas haviam ficado mais positivas; ela havia mudado para um novo provedor, Upful Groupvine, cujo produto incansavelmente positivo era o equivalente musical do Good News Channel. Cruzando as despesas dela com os registros de sua financeira e seus clientes varejistas, obteve uma lista de tudo o que havia comprado na última semana" (Gibson, 1999:53).

Combinando intuição e análise dos padrões informacionais gerados nas compras, no consumo de músicas ou na mudança de provedor, Laney capta mínimas mudanças na conduta e no estado de espírito da mulher que observa. É claro que estamos diante de um caso-limite. Mas talvez não fosse exagerado afirmar que esse é o horizonte almejado e pouco a pouco construído pela crescente colonização das redes e a acelerada integração dos bancos de dados.

Alison Shires intui que está sendo observada; e Laney intui que ela intui. Mas quantos são como ela? A inocên- cia do usuário do ciberespaço, e principalmente do usuário brasileiro, que freqüentemente nem sabe da existência dos cookies, esses pequenos bits de software plantados em seu computador para coletar parte de seus dados pessoais, só encontra paralelo na ignorância generalizada sobre a relação estreita que se estabelece entre o controle do acesso à esfera digital e o controle do acesso às informações do usuário.

Todos sabem que o capitalismo passa por uma verdadeira mutação, em virtude da aceleração tecnocientífica e econômica que tomou conta do planeta e se converteu em estratégia de dominação, em escala global. Diversos termos tentam enunciar essa passagem e capturar os sinais dos novos tempos: era da informação, sociedade pós-industrial, pós-modernidade, revolução eletrônica, sociedade do espetáculo, globalização, etc. Por outro lado, todos pressentem que a cultura contemporânea está sendo rapidamente desmaterializada, isto é, digitalizada e reelaborada na esfera da informação. Analisando o processo no campo artístico, Mark Dery, por exemplo, considera que a cibercultura está prestes a atingir a "velocidade de escape", essa velocidade em que um corpo vence a atração gravitacional de outro corpo, como por exemplo uma nave espacial quando abandona a Terra; em outras palavras: Dery pensa que a cibercultura está prestes a romper o limite que a prende ao mundo geográfico, mundo da matéria. Como se o mundo virtual se desprendesse do mundo atual, ganhando dinâmica própria (Dery, 1998).

Entre as muitas propostas de leitura do que está ocorrendo, há uma, recentíssima, que busca compreender o impacto da aceleração econômica e tecnocientífica na relação fundamental da sociedade capitalista moderna: a relação de propriedade. Trata-se do livro de Jeremy Rifkin, The age of access, que explora as tendências suscitadas pelo processo de digitalização no que está sendo chamado de "nova economia" (Rifkin, 2000).

Rifkin descobre que o papel da propriedade está mudando radicalmente e considera que as implicações de tal mudança para a sociedade são enormes e de longo alcance. No seu entender, “A propriedade é uma instituição lenta demais para ajustar-se à velocidade quase aberrante da cultura do nanosegundo. A propriedade se baseia na idéia de que a posse de um bem físico ou de parte de uma possessão num extenso período de tempo tem valor. 'Ter', 'manter', e 'acumular' são conceitos cultivados. Agora, entretanto, a velocidade da aceleração tecnológica e o ritmo vertiginoso da atividade econômica freqüentemente tornam a noção de propriedade problemática. 
Num mundo de produção flexível, de contínuas inovações e upgrades, e de ciclos de vida da produção cada vez mais curtos, tudo se torna quase imediatamente ultrapassado. Faz cada vez menos sentido ter, manter e acumular numa economia em que a mudança é a única constante" (Rifkin, 2000:6).

$\mathrm{Na}$ estratégia da aceleração, parece que não vale mais a pena possuir. Com efeito, observando a performance das empresas e a conduta dos consumidores, Rifkin percebeu que tanto umas quanto os outros tendem cada vez mais a substituir a propriedade pelo acesso, a substituir a relação de compra e venda pela relação de fornecimento e uso. Isso não significa porém que a propriedade será questionada ou abolida na nova era que Rifkin anuncia, a Era do Acesso: a propriedade continua existindo mas é muito menos provável que seja trocada em mercados. Em vez disso os fornecedores, ou provedores, como se diz na nova economia, mantêm a propriedade e alugam, fazem leasing ou cobram uma taxa de admissão, uma assinatura, uma mensalidade para o seu uso no curto prazo. A transferência de propriedade entre vendedores e compradores dá então lugar ao acesso a curto prazo entre provedores e clientes operando numa relação de rede (Rifkin, 2000:4-5).

Rifkin define os novos tempos da seguinte maneira: “A Era do Acesso é definida, acima de tudo, pela crescente transformação de toda experiência humana em mercadoria. Redes comerciais de toda forma ou tipo tecem uma teia em torno da totalidade da vida humana, reduzindo cada momento da experiência vivida à condição de mercadoria. Na era do capitalismo proprietário, a ênfase recaía na venda de bens e serviços. Na economia do ciberespaço, a transformação de bens e serviços em mercadorias tornase secundária face à transformação das relações humanas em mercadorias. Numa nova e acelerada economia de rede em permanente mudança, prender a atenção dos clientes e consumidores significa controlar o máximo possível do seu tempo. Passando das unitárias transações de mercado, que são limitadas no tempo e no espaço, para a mercantilização de relações que se estendem abertamente no tempo, a nova esfera comercial garante que parcelas cada vez maiores da vida diária fiquem presas no final da linha" (Rifkin, 2000:97).

Com a Era do Acesso, dá-se portanto uma mudança de perspectiva que traz para o centro da atividade econômica o controle do tempo do consumidor. O consumidor não é mais um alvo do mercado, ele torna-se o próprio mercado, cujo potencial é preciso conhecer, prospectar e processar. Pois como argumentam os consultores de marketing
Don Peppers e Martha Rogers, não se trata mais de tentar vender um único produto para o maior número possível de consumidores, mas sim de tentar vender para um único consumidor o maior número possível de produtos, durante um longo período de tempo. Em outras palavras, é preciso poder acessar o consumidor e torná-lo cativo (apud Rifkin, 2000:98).

Tendo em vista a nova perspectiva que se abria, os economistas e marketeiros começaram a calcular a existência do consumidor, concebendo-a em termos de experiências de vida traduzíveis em potenciais experiências de consumo. É o que denominam "valor do tempo de vida", uma medida teórica de quanto vale um ser humano se cada momento de sua vida for transformado em mercadoria de uma ou outra maneira. Visando calcular o valor do tempo de vida de um consumidor, projeta-se então o valor presente de todas as futuras compras contra os custos de marketing e de atendimento investidos para criar e manter uma relação duradoura. Assim, estima-se por exemplo que a fidelidade de um consumidor médio de um supermercado norte-americano vale mais de US\$3,600 por ano. Otimizar o potencial valor do tempo de vida do consumidor passa então a ser a prioridade máxima. Ora, é aqui que a informação torna-se uma arma fundamental. Pois como escreve Rifkin, "as novas tecnologias de informação e de telecomunicações da economia de rede tornam possível determinar o valor do tempo de vida de uma pessoa. O feedback eletrônico e o código de barras permitem que as empresas recebam continuamente informação atualizada sobre as compras dos clientes, fornecendo perfis detalhados dos estilos de vida dos consumidores - suas preferências alimentícias, guarda-roupa, estado de saúde, opções de lazer, padrão de suas viagens. Através de apropriadas técnicas de modelização computadorizada, é possível utilizar essa massa de dados brutos de cada indivíduo para antecipar futuros desejos e necessidades e mapear campanhas direcionadas para engajar os consumidores em relações comerciais de longo prazo" (Rifkin, 2000:99).

Controlar os consumidores e principalmente monitorar as potencialidades de cada uma das dimensões de suas vidas tornam-se uma exigência do próprio processo, impondo a coleta e o tratamento de informações. Ora, se lembrarmos que uma parcela cada vez maior da vida e das atividades do homem contemporâneo tende a passar pelas redes, quem melhor colocado para acessar os seus dados senão os provedores de acesso ao ciberespaço? Como observa Emilio Pucci, é preciso ter em mente que, se por um lado as redes oferecem um enorme fluxo de informa- 
ções no sentido provedor-usuário, por outro, preciosíssimos fluxos partem deste último para o gestor do serviço, compostos sobretudo de dados sobre os hábitos e a identidade dos utilizadores (Pucci, 1995:48). Por outro lado, se acessar e processar as informações dos usuários é quase uma decorrência natural das atividades dos provedores, a recíproca não é verdadeira: é muito difícil que o internauta comum tenha meios de acessar as informações das empresas que não estão destinadas à divulgação.

Desde que se explicitou a estreita relação entre acesso ao ciberespaço e acesso aos dados do usuário, temos assistido a um duplo movimento. No plano econômico instaurou-se a corrida do capital global pelo controle e colonização das redes, estratégia que consistiu num primeiro momento em promover a privatização das telecomunicações para, numa segunda fase, assegurar a privatização de todo o campo eletromagnético, o que está em vias de acontecer. Mas por outro lado, no plano jurídico-político, a possibilidade de extensa e intensa exploração das informações sobre o usuário colocou em questão o impacto das novas tecnologias sobre a cidadania e a democracia, uma vez que ficavam abalados o direito à privacidade e a liberdade de informação.

A responsabilidade pelas discussões sobre a criptografia, o clipper chip e a assinatura eletrônica, segundo alguns, é uma ameaça à cidadania e à democracia; outros acreditam que a questão da segurança, do sigilo e da proteção dos dados no ciberespaço interessa principalmente às empresas, porque transações confiáveis com o dinheiro eletrônico exigiriam um "sujeito virtual autêntico" (Marchisio, 1996:143 e ss.).

Qual é a vulnerabilidade do cidadão brasileiro diante do poder das grandes corporações e do Estado que podem acessar e manipular seus dados capturados nas redes digitais?

$\mathrm{O}$ artigo $5^{\circ}$ da Constituição protege a privacidade e a liberdade de informação: o inciso X declara invioláveis a intimidade, a vida privada, a honra e a imagem das pessoas; o XI, sua casa; o XII, o sigilo de sua correspondência, das comunicações telegráficas, de dados e das comunicações telefônicas; o XIV assegura a todos o acesso à informação e resguarda o sigilo da fonte, quando necessário ao exercício profissional; o XXXIII garante a todos o direito a receber dos órgãos públicos informações de seu interesse particular, ou de interesse coletivo ou geral, ressalvadas aquelas cujo sigilo seja imprescindível à segurança da sociedade e do Estado. Por sua vez, a Declaração Universal dos Direitos do Homem afirma em seu artigo 12: "Ninguém será sujeito a interferência na sua vida privada, na sua família, no seu lar ou na sua correspondência, nem a ataque à sua honra e reputação. Todo homem tem direito à proteção da lei contra tais interferências ou ataques." Finalmente, seu artigo 19 enuncia: "Todo homem tem direito à liberdade de opinião e expressão; este direito inclui a liberdade de, sem interferência, ter opiniões e de procurar, receber ou transmitir informações e idéias por quaisquer meios e independentemente de fronteiras."

A esses dispositivos legais, veio acrescentar-se, em julho de 1996, uma lei que regulamenta o inciso XII do artigo $5^{\circ}$ da Constituição, mais especificamente a interceptação de comunicações telefônicas, de informática ou telemática. Mas tal lei, que visava principalmente a questão da escuta telefônica, nada diz sobre todas as ações e práticas que são objeto de nossa atenção nesta conferência. Na verdade, como a proteção constitucional à privacidade antecedeu as possibilidades técnicas de acesso e manipulação dos dados a partir das redes digitais, há um evidente vazio legal que aparentemente deixa os internautas brasileiros indefesos. Desde 1996, porém, tramitaram tanto no Senado quanto na Câmara Federal projetos de lei visando regular a prestação de serviço por redes de computadores, assegurar a privacidade dos usuários, combater os delitos informáticos, e normatizar a veiculação da pornografia. Sua leitura, entretanto, sugere muito mais uma preocupação em proteger o Estado e as empresas contra os hackers do que a inviolabilidade do cidadão comum. Tanto assim que um deles, o Projeto de Lei no 84, de 1999, do deputado Luiz Piauhylino, propõe, no art. 16: "Nos crimes definidos nesta lei somente se procede mediante representação do ofendido, salvo se cometidos contra o interesse da União, Estado, Distrito Federal, município, órgão ou entidade de administração direta ou indireta, empresa concessionária de serviços públicos, fundações instituídas ou mantidas pelo poder público, serviços sociais autônomos, instituições financeiras ou empresas que explorem ramo de atividade controlada pelo poder público, casos em que a ação é pública incondicionada." ${ }^{2}$ Ora, pode-se imaginar que o cidadão comum dificilmente terá até mesmo a possibilidade de descobrir que foi ofendido.

Suponhamos, por exemplo, que um grande banco privado brasileiro se associe a um provedor global de acesso à Internet. A parceria será evidentemente anunciada como um ganho para os clientes, que poderão contar com serviços mais ágeis, tecnologias mais avançadas, etc. Mas como não pensar que os milhões de clientes do banco são um ativo interessantíssimo para um provedor que acaba de 
aportar no país? Como não pensar na potencial sinergia do cruzamento de seus cadastros com o banco de dados do provedor? Como não imaginar que essa soma de $1+1=3$, pela proliferação de novos negócios que ela pode propiciar? E como acreditar que tanto os clientes do banco quanto os usuários do provedor ficariam sabendo, caso seus dados pessoais fossem usados sem seu prévio consentimento?

Num país de capitalismo selvagem como o nosso, onde a cidadania nem chegou a ser plena e já está em vias de desmanche, é de se suspeitar que nossa vulnerabilidade seja grande e será ainda maior. Basta evocar um exemplo, colhido sem esforço: o jornalista Josias de Souza publicou recentemente, na Folha de S.Paulo, que no início deste ano era possível comprar em São Paulo, por apenas R $\$ 4.000$, o banco de dados da Receita Federal de 1996, contendo as informações sigilosas de 11,5 milhões de brasileiros - 7,6 milhões de pessoas físicas e 3,9 milhões de empresas! Renda, faturamento, ocupação, ramo de atividade, patrimônio, endereços, números de telefones, tudo vendido em CDs, para festa do marketing e da mala-direta. O banco havia sido roubado no início de 1997 dentro da própria Serpro, e ao que tudo indica por funcionários graúdos da empresa (Souza, 2000: A-13). Quem acredita ser possível responsabilizar o Estado por essa gigantesca violação, que em qualquer país sério teria no mínimo provocado uma crise política e o corte de algumas cabeças? Podem os contribuintes exigir um ressarcimento por danos que eles não têm condições de comprovar e muito menos contabilizar, mesmo quando desconfiarem que suas informações estão sendo criminosamente utilizadas?

O problema é muito mais complexo do que parece e comporta muitas dimensões. Não é só o cidadão que, reduzido à condição de consumidor cativo, fica superexposto e tem a sua privacidade violada. Na verdade, na nova economia, a própria existência do indivíduo é posta em questão. Aqueles que processam a sua vida descendo a níveis microscópicos não o concebem mais como sujeito, mas sim como gerador de padrões informacionais que é preciso manipular; aos olhos de quem opera com o valor do tempo de vida, o indivíduo dissolve-se em fluxos de dados. Entretanto, não é só no plano da informação digital que o indivíduo desaparece, - também no plano da genética assistimos à sua desintegração. Pois como observa Paul Virilio, o individuum, literalmente o que é indivisível, deixa de sê-lo no plano molecular.

Basta lembrar o caso Moore, estudado por Bernard Edelman em La personne en danger. Como se sabe, em 1976, John Moore soube que era portador de um tipo raro de leucemia e foi se tratar no centro médico da Universidade da Califórnia; lá tiraram-lhe o baço e, sem seu consentimento, extraíram do material removido uma linhagem de células que foi imortalizada, porque continha uma verdadeira mina de ouro para a pesquisa sobre determinadas formas de câncer. Em 1984, as informações genéticas foram evidentemente patenteadas pela equipe médica e em seguida comercializadas para o laboratório suíço Sandoz; em 1990, seu valor chegava a algo perto de três bilhões de dólares. Descobrindo o que ocorrera, Moore moveu um processo reivindicando o direito às suas células; isto é: reivindicando a "legítima propriedade" sobre seus "bens corporais".

Os advogados dos médicos argumentaram que o DNA das células de Moore não era uma parte dele, sobre a qual ele tivesse o poder extremo de dispor durante a sua vida. Comentando o argumento, o jurista francês observa: "Isto significa que do ponto de vista microbiológico, quer dizer do ponto de vista dos componentes do gene, não haveria mais indivíduo enquanto tal. Para dizer as coisas cruamente, a pessoa humana não existiria nos segredos de suas células. Vejamos o deslocamento: não se trata mais de saber se uma pessoa tem ou não um direito sobre suas células, mas de sustentar que ela não tem existência em suas células. Assim, por um lado, nada se oporia a que elas sejam postas à venda, e por outro, uma vez desprovidas de qualquer personalidade, "elas não teriam mais proprietário". Na lógica do direito de propriedade, continua Bernard Edelman, tal argumento pesava pouco. Com efeito, pouco importava que Moore existisse ou não em suas células, já que era proprietário delas. O direito de propriedade não quer saber se o objeto sobre o qual ele se aplica é o suporte da identidade do proprietário! Pensando bem, esse expediente até tendia mais no sentido do direito de propriedade: pois se no DNA não há nada de humano, é porque a célula é uma coisa e, conseqüentemente, pode ser objeto de propriedade. Portanto, teria sido lógico que o tribunal descartasse esse argumento fazendo valer, precisamente, que o poder extremo de dispor é o direito do proprietário. E no entanto, muito curiosamente, ele recuou diante dessa lógica" (Edelman, 1999:298-299).

O tribunal considerou que o homem possui o direito imprescritível à sua identidade e pouco importa que esse direito seja protegido pela noção de privacy (direito de personalidade), de property (direito de propriedade) ou de publicity (direito de tirar proveito dos "atributos" da personalidade: voz, imagem, etc.) desde que a proteção seja efetiva. No caso Moore o tribunal concluiu que "um 
paciente deve ter o poder extremo de controlar o que vai ser de seus tecidos. Admitir o contrário abriria a porta a uma invasão maciça de sua privacy e de sua dignidade em nome do progresso médico."

Mas como bem observa Bernard Edelman tal conclusão, ao reconhecer o direito de personalidade, parece entrar em contradição com o direito de propriedade: "Na lógica da propriedade, escreve o jurista, as células são coisas, "bens mobiliários corporais". Não é de se espantar então que se possa negociá-las, transferi-las, lucrar com elas. Mas na lógica da privacy, as células exprimem a identidade da pessoa. Ora, o homem não pode se vender, sob pena de reduzirse ao estado do escravo, e as células deveriam ficar fora do comércio jurídico. No entanto, o tribunal parece não ter tido dificuldade alguma em combinar o direito de propriedade com o right of privacy. Como compreender essa conciliação?" (Edelman, 1999:299-300).

Edelman demonstra que a possível contradição foi resolvida pelo direito de publicidade, que confere ao indivíduo a possibilidade de explorar sua imagem, seu personagem, e permite que seus atributos possam adquirir o valor de um "bem", como uma marca ou uma grife, por exemplo. Em outras palavras: a imagem do indivíduo torna-se um produto relativamente independente da pessoa que ela representa: de um lado, conserva algo de sua origem, de outro, leva sua vida comercial de modo independente. Assim, o tribunal tratou as informações genéticas de Moore como a imagem - suas células são ao mesmo tempo a pessoa enquanto privacy e a pessoa enquanto publicity, isto é, enquanto pessoa que pode ser comercializada. Por isso Edelman concluirá que o tribunal resolve a contradição denegando-a: "O direito de propriedade sobre os produtos de seu corpo constitui o corpo como escravo; em contrapartida, a pessoa não é senão o que permite ao sujeito colocar-se em regime de exploração. $\mathrm{O}$ right of publicity está prestes a absorver o right of privacy; o mercado absorve a subjetividade" (Edelman, 1999:302).

Traduzido em informação digital e genética, o indivíduo torna-se divisível, ou para usar o termo empregado por Gilles Deleuze, "dividual”. O sujeito não é mais modelado de uma vez por todas mas sim permanentemente modulado, segundo uma nova lógica de dominação que nos faz passar da sociedade disciplinar para a sociedade de controle, segundo a expressão cunhada por William Burroughs e emprestada por Deleuze.

É interessante observar como para o filósofo a passagem de uma sociedade a outra se expressa como crise dos espaços fechados, inclusive o espaço doméstico e a "interioridade" do indivíduo, como abertura dos grandes meios de confinamento que haviam sido estudados por Foucault, e a sua substituição por novas formas de controle aberto. "As sociedades disciplinares têm dois pólos, escreve Deleuze: a assinatura que indica o indivíduo, e o número de matrícula que indica sua posição numa massa. É que as disciplinas nunca viram incompatibilidade entre os dois, e é ao mesmo tempo que o poder é massificante e individuante, isto é, constitui num corpo único aqueles sobre os quais se exerce, e molda a individualidade de cada membro do corpo (...). Nas sociedades de controle, ao contrário, o essencial não é mais uma assinatura nem um número, mas uma cifra: a cifra é uma senha, ao passo que as sociedades disciplinares são reguladas por palavras de ordem (tanto do ponto de vista da integração quanto da resistência). A linguagem numérica do controle é feita de cifras, que marcam o acesso à informação, ou a rejeição.

Não se está mais diante do par massa-indivíduo. Os indivíduos tornaram-se "dividuais", divisíveis, e as massas tornaram-se amostras, dados, mercados ou "bancos". (Deleuze, 1992:222).

Este artigo teve por título Limites e Rupturas na Esfera da Informação. Mas agora, ao terminar de escrevê-lo, percebe-se que ele é impróprio. Diversas rupturas operadas na esfera da informação foram aqui apontadas; entretanto, não se pode dizer o mesmo dos limites. Muito ao contrário, creio que o poder de intervenção da tecnociência e da economia sobre o corpo e a mente do indivíduo, e até mesmo sobre a própria natureza humana, parece ilimitado.

\section{NOTAS}

Conferência apresentada na $52^{\mathrm{a}}$ Reunião da SBPC, realizada na Universidade Nacional de Brasília, dia 13 de julho de 2000.

1. Ver: The New York Times News Service em português, www.uol.com.br Tradução de Déborah Weinberg.

2. Projeto de Lei no 84 , de 1999. http://infojur.ccj.ufsc.br/arquivos/informaticajuridica/ normas/projetodelei $84 . \mathrm{htm}$

\section{REFERÊNCIAS BIBLIOGRÁFICAS}

BLOOM, D. "Internet oferece voyeurismo em tempo integral". Los Angeles Daily News, 1/7/2000.

DELEUZE, G. Conversações. Rio de Janeiro, Ed. 34 (Trad. de Peter Pál Pelbart), 1992.

DERY, M. Velocidad de escape - La cibercultura en el final del siglo. Madrid, Ed. Siruela, 1998 (Trad. de Ramón Montoya Vozmediano).

EDELMAN, B. La personne en danger. Doctrine Juridique. Paris, Presses Universitaires de France, 1999.

GIBSON, W. Idoru. São Paulo, Conrad Livros, 1999 (Trad. de Leila de Souza Mendes). 
MARCHISIO, O. "Cyberbucks e identità". In: (Bifo) BERARDI, F. (ed.). Cibernauti-Tecnologia, comunicazione, democrazia. Roma, Castelvecchi, 1996.

PUCCI, E. "Il mercato dell'interattività". In: (Bifo) BERARDI, F. (ed.) Cibernauti - Internet e il futuro della comunicazione. Roma, Castelvecchi, 1995.
RIFKIN, J. The age of access - The new culture of hypercapitalism, where all of life is a paid-for experience. Nova York, Jeremy P. Tarcher/Putnam, 2000. SOUZA, J. de. "Dados sigilosos da Receita vazaram do Serpro". Folha de S. Paulo, 2/7/2000.

VIRILIO, P. La bombe informatique. Paris, Galilée, 1998. 